\title{
Web Browser
}

National Cancer Institute

\section{Source}

National Cancer Institute. Web Browser. NCI Thesaurus. Code C142748.

A software tool that enables Internet navigation to Web sites and other online resources using Hypertext Transfer Protocol (HTTP). 